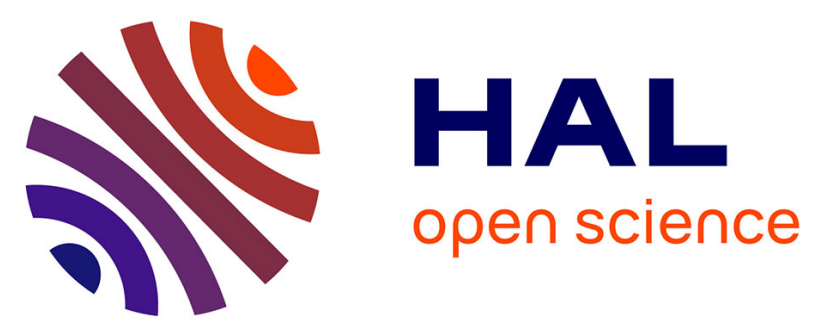

\title{
Postdetoxification Factors Predicting Alcohol-Related Emergency Room Visits 12 to 24 Months After Discharge: Results from a Prospective Study of Patients with Alcohol Dependence
}

Aymery Constant, Antonia Le Gruyer, Caroline Le Lan, Françoise Riou, Romain Moirand

\section{To cite this version:}

Aymery Constant, Antonia Le Gruyer, Caroline Le Lan, Françoise Riou, Romain Moirand. Postdetoxification Factors Predicting Alcohol-Related Emergency Room Visits 12 to 24 Months After Discharge: Results from a Prospective Study of Patients with Alcohol Dependence. Alcoholism: Clinical and Experimental Research, 2015, 39 (7), pp.1236-1242. 10.1111/acer.12753 . hal-01162375

\section{HAL Id: hal-01162375}

\section{https://hal-univ-rennes1.archives-ouvertes.fr/hal-01162375}

Submitted on 17 Nov 2015

HAL is a multi-disciplinary open access archive for the deposit and dissemination of scientific research documents, whether they are published or not. The documents may come from teaching and research institutions in France or abroad, or from public or private research centers.
L'archive ouverte pluridisciplinaire HAL, est destinée au dépôt et à la diffusion de documents scientifiques de niveau recherche, publiés ou non, émanant des établissements d'enseignement et de recherche français ou étrangers, des laboratoires publics ou privés. 


\section{Post-detoxification factors predicting alcohol-related emergency room visits}

\section{2 to 24 months after discharge: Results from a prospective study of patients with alcohol dependence}

Aymery Constant, $\mathrm{PhD},{ }^{1,}$, Antonia Le Gruyer, $\mathrm{MD}^{2,3}$, Caroline Le Lan, $\mathrm{MD}^{2}$, Francoise Riou MD, PhD, ${ }^{3,4}$, Romain Moirand, MD, $\mathrm{PhD},{ }^{2,3,5}$

(1) EHESP School of Public Health, F-35043, Rennes, France

(2) CHU de Rennes, Unité d'Addictologie , F-35033 Rennes, France

(3) Univ Rennes 1, Faculté de Médecine, F-35043 Rennes, France

(4) Department of Public Health, Rennes University Hospital, F-35033, France.

(5) INSERM UMR 991, F-35000, Rennes, France

\section{Corresponding author:}

Aymery Constant

Ecoles des Hautes en Santé Publique

Avenue du Prof. Leon Bernard, 35043 Rennes Cedex, France

\section{Aymery.constant@ehesp.Fr}

Tel : +33299022593

Fax : +332992625 
The study was supported by the funding body of the Rennes University Hospital Addiction Unit, the "Association Fer et Foie”.

Authors declare no conflict of interest 


\section{ABSTRACT}

\section{Background}

Relapse is common in patients with alcohol dependence, even after detoxification. The aims of this prospective study were to investigate changes affecting patients during the first 6 months after discharge from hospitalization for detoxification and to determine the influence of these changes on the likelihood of alcohol-related emergency room (ER) visits in the following 18-month period.

\section{Methods}

The study included 88 patients hospitalized for participation in a detoxification program in the addiction department of a university hospital in Rennes, France. Alcohol consumption, psychiatric symptoms, and life events were investigated by trained addiction specialists during hospitalization and 6 months afterwards. For each patient, the number of alcoholrelated ER visits in the last 6 months was prospectively recorded at the hospital 12, 18, and 24 months after hospitalization. The rate ratios of ER visits as a function of sociodemographic variables and changes observed 6 months after discharge were estimated using Poisson regression with autoregressive errors.

\section{Results}

Nearly half of the patients (47.7\%) had ER visits in the 12- to 24-month period following discharge. The likelihood of ER visits was higher for patients living with friends/parents and for those with aggravated psychiatric symptoms, negative changes in their family life, and who had had a medical follow-up in the 6 months after discharge. In contrast, the likelihood of ER visits was lower for patients living with children and those with improved psychiatric 
morbidity. Alcohol consumption and psychiatric symptoms at baseline had no significant effect.

\section{Conclusions}

Monitoring changes in psychiatric symptoms and family life early after a detoxification program may help identify patients who are vulnerable to relapse in the subsequent 18-month period. Systematic screening for these changes as early as possible, in combination with appropriate treatment and the establishment of a social support system, could be fundamental in avoiding further relapses and ER visits.

Keywords: Alcohol dependence; detoxification; emergency room visits; prospective study; determinants analysis 


\section{Introduction}

Alcohol remains a major threat to public health in Europe and in most industrialized countries. Alcohol misuse is associated with an increased risk of injury, violence, and disease (Korcha et al., 2014). In France, alcohol accounted for 49,000 deaths in 2009, mainly from cancer, circulatory and digestive system diseases, and external causes such as injury and suicide (Guerin et al., 2013). Patterns of heavy drinking and alcohol abuse/dependence are significant risk factors for premature mortality (Zureik and Ducimetiere, 1996, Liskow et al., 2000). While achieving sustained abstinence or moderation is crucial to improve both health and quality of life (Kline-Simon et al., 2014), some issues, such as psychiatric disorders and withdrawal syndrome, can jeopardize these outcomes (Curran et al., 2000, Hasin et al., 2000, Snow and Anderson, 2000, Strowig, 2000, Suter et al., 2011). Such problems can be monitored and adequately treated in healthcare settings during the 7- to 14-day hospitalization period of most alcohol detoxification programs (Ruusa et al., 2000). However, some events may put the patient at risk in the period following hospital discharge. Evidence from cohort studies in the general population indicates that some major life events, including those that affect the individual's family, social, or professional life, influence excessive alcohol drinking among men and women; although, this effect is not necessarily permanent (Tamers et al., 2014, Zins et al., 2003, Yaogo et al., 2014). For individuals with alcohol dependence, life events such as divorce or separation might be associated with relapse (Pilowsky et al., 2013) and shorter time to death (Lewis et al., 1995). A retrospective study that compared interviews with untreated former problem drinkers who maintained stable abstinence or drinking in moderation for more than 2 years with interviews with current drinkers found that improved life circumstances had a positive effect during the first year of maintenance (King and Tucker, 1998). 
It should be stressed that prospectively assessing treatment outcomes after detoxification remains a difficult task. First, a high proportion of patients with alcohol dependence are lost to follow-up (Spinatsch, 1992). Those who are difficult to locate or who go missing tend to have poorer social functioning and to be residentially unstable during the follow-up period, and these characteristics tend to correlate with worse drinking outcomes. Those who are willing to be interviewed tend to be residentially stable and show better interpersonal adjustment at follow-up (Mackenzie et al., 1987, Walton et al., 1998). In addition, there is no clear consensus regarding the outcomes that determine whether a treatment that addresses addictive behavior is effective. The term "recovery", for instance, is generally avoided by researchers and might be interpreted as having different meanings by clinicians, social workers, and the public (White, 2007, Witbrodt et al., 2015). Reduced-risk drinking is increasingly discussed as a valuable option for patients who do not want to or who cannot quit (van Amsterdam and van den Brink, 2013), but this raises the question of the criteria used to evaluate the outcome.

Using the number of alcohol-related emergency room (ER) visits as a surrogate measure of severe relapse may be useful in longitudinal studies. Alcohol misuse frequently contributes to a wide range of severe health issues that require immediate medical care and, thus, ER visits (Wu et al., 2012, Minassian et al., 2013, Hoskins and Benger, 2013). When technically feasible, such issues are systematically recorded in hospital information systems together with alcohol involvement. Accordingly, data collection requires few resources and represents a valid and objective measure of relapse to alcohol misuse (Young et al., 2004), even for patients lost to follow-up.

Investigating the causal relationship between changes in patients’ lives that occur after they participate in a detoxification program and their ensuing alcohol-related issues might be useful for early identification of those who are vulnerable to relapse. The aims of this 
prospective study were to investigate changes within 6 months after discharge in patients hospitalized for detoxification and to determine the influence of these changes on the likelihood of alcohol-related emergency room (ER) visits in the following 18-month period. 


\section{Materials and Methods}

\section{Participants}

The study protocol was approved by the local research ethics committee, and informed consent was obtained from all participants. All patients aged $>18$ years who were hospitalized for alcohol detoxification between November 02, 2009 and April 30, 2010 in the alcohol unit of the university hospital and were living in Rennes, France or its surrounding areas were eligible for inclusion in the study. The exclusion criteria were severe cognitive impairment and refusal. Patients were referred to the detoxification program by their primary care practitioners or by outpatient addiction treatment facilities. Detoxification consisted of alcohol withdrawal using personalized treatment with diazepam, careful multidimensional evaluation of the patient, and the establishment of a treatment plan for aftercare. The intent of this study was to follow the entire cohort for two years with a visit every 6 months.

\section{Procedure and baseline assessment}

Patients were interviewed by trained addiction specialists (RM, CLL, and ALG) during their hospitalization and again 6 months later. The following data were collected during hospitalization: gender; age in years; living status (alone, with friends or parents, with a partner); living with children (yes/no); level of education (<high school vs. >high school); employment status (employed vs. unemployed/retired); and driving license status (active vs. suspended/lost/never had). Alcohol dependence severity was assessed by counting the number of DSM-IV criteria for alcohol dependence observed, These comprise 1) increased alcohol tolerance, 2) withdrawal syndrome, 3) where alcohol is taken in larger amounts or over a longer period than intended, 4) persistent desire or unsuccessful efforts to cut down or control alcohol use, 5) a great deal of time is spent in activities necessary to obtain alcohol, use alcohol or recover from its effects, 6) important social, occupational, or recreational 
activities are given up or reduced because of alcohol use, and, 7) alcohol use is continued despite knowledge of having a persistent or recurrent physical or psychological problem that is likely to have been caused or exacerbated by the alcohol (Sheehan et al., 1998). Chronicity was assessed by investigating the previous history of alcohol-related ER visits and the difference in time since the onset of dependence (i.e. loss of control over alcohol for the first time) and baseline (in years). The presence of psychiatric symptoms was investigated with semi-structured interviews using DSM-IV criteria for mood and anxiety disorders. Psychotic symptoms were also screened for so that a referral could be made to a psychiatrist. Whenever possible, the clinician made a distinction between symptoms that were probably due to alcohol consumption or withdrawal and symptoms that were probably related to a cooccurring psychiatric disease. Alcohol consumption was estimated using the Alcohol Timeline Follow-back (TFLB). During this validated procedure, the interviewer worked with the participant to review each of the past 28 days to assess how many standard alcohol drinks were consumed (Cervantes et al., 1994). In this study, the baseline level of alcohol consumption was estimated using the number of excessive drinking days over the last month, defined as exceeding 6 units per day for men and 4 units per day for women. The alcohol drinking pattern was classified as "moderate” if men consumed less than 15 units per week (12 units for women) and did not exceed 6 units per day (4 units for women); while, alcohol consumption was considered “excessive” if patients exceeded those limits at least twice monthly.

\section{Changes observed 6 month after discharge}

It was considered that patients had a medical follow-up in the 6 months after discharge if they had had at least one medical visit per month for alcohol dependence during this period with a health professional (general practitioner, psychiatrist, addictologist). This information 
was obtained during the follow-up assessment of the patient and cross-checked by interviewing the patient's general practitioner and the staff at the specialized addiction care units in the area. Participants were classified into three categories according to changes in their alcohol consumption over the same period: “improved” if the alcohol consumption level (in the month prior to each evaluation) decreased from "excessive" to "moderate/absent" or from "moderate” to "absent”; "aggravated" if it increased (from "moderate” to "excessive” for instance); and "unchanged" if they maintained the same alcohol drinking pattern. Participants were also classified into three categories according to changes in their psychiatric symptoms during the same period, namely "improved" if symptoms were clinically significant at baseline but controlled 6 months later; "aggravated" if symptoms were controlled/absent at baseline but emerged significantly 6 months later; and "unchanged" if symptoms remained identical during this period. All changes reported by patients as differing from baseline in regards to their professional, social, or family lives were recorded. Changes were based on patient self-report and qualitatively evaluated by physicians as "positive” or "negative", or as "unchanged" if there were no changes. Thus, a separation/divorce could be considered as being a positive change by physicians in the case of a violent partner (Snow and Anderson, 2000); while, meeting friends could be considered as a negative change when they contributed to the individual's heavy drinking pattern (Lau-Barraco and Collins, 2011). Changes in social life consisted mainly of improvements or worsening of one's financial or personal situation (e.g. being officially recognized as being disabled).

\section{Follow-up assessment}

The numbers of alcohol-related ER visits in the last 6 months were prospectively collected at 12 months (M12), 18 months (M18), and 24 months (M24) after hospitalization from the Rennes University Hospital's information system. Motives for admission were 
alcohol-related injury, acute intoxication, and referral to the ER after being apprehended for drunk and disorderly behaviors by the police.

\section{Statistical analyses}

Categorical data were expressed as numbers $(\mathrm{N})$ and percentages (\%), while numerical data were expressed as means and standard deviations. Baseline characteristics were compared using the Chi-square Test and one factor analysis of variance. The number of alcohol-related ER visits in the last 6 months was recorded for each patient during the 24month study period, but only those recorded at M12, M18, and M24 were selected as outcomes to avoid co-occurrence with changes observed 6 months after discharge. Because ER visits were assessed several times during the follow-up period, estimates were computed using the generalized estimating equation (GEE) technique, which extends the generalized linear model to include analysis of repeated measurements or other correlated observations (Zeger and Liang, 1986, Zeger et al., 1988). Since our study outcome was a count variable (number of ER visits in the last 6 months), we used generalized linear Poisson regression models with autoregressive errors to estimate the rate ratios (RRs) of alcoholrelated ER visits at M12, M18, and M24 as a function of sociodemographic variables and changes observed 6 months after discharge. Estimates (model 1) were expressed as RR with 95\% confidence intervals (RR [95\% CI]), adjusted with baseline values for changes in alcohol consumption and psychiatric symptoms. Significant estimates from model 1 were analyzed in a multivariate model, i.e. model 2. Statistical analyses were performed using the SPSS statistical package, version 19 (SPSS, Chicago, Illinois, United States). 


\section{Results}

The study included 103 patients hospitalized for detoxification. However, 15 of them died during the 24-month study period: 4 between baseline and M6, 1 between M6 and M12, 5 between M12 and M18, and 5 between M18 and M24. Comparison tests showed no differences at baseline between patients who died and others.

Nevertheless, the prevalence of ER visits was estimated among the 88 patients who completed the entire study period to avoid any computing bias. In the 12- to 24-month period after hospitalization for alcohol detoxification, a total of 138 alcohol-related ER visits were recorded for 42 of the 88 included patients (47.7\%). A total of 17 patients had one ER visit, 12 patients had 2-3 visits, 8 patients had $4-5$ visits, and 5 patients had 7-16 visits during this period. The percentage that went to the ER changed little over time: $27.3 \%, 23.9 \%$, and 28.4\% of patients had an alcohol-related ER visit at M12, M18, and M24, respectively.

Of the 88 included patients (Table 1), 73 (83\%) were men, the average age was 45.2 years, and 56 (63.6\%) did not complete high school. Most participants lived alone (56.8\%) without children (73.9\%). Most were employed (70.5\%) but lacked a valid driving license (59.1\%). All patients met the DSM-IV criteria for dependence, with a majority (59\%) reporting 6 or 7 criteria out of 7 . Alcohol dependence lasted for an average of 18.4 years and 62.5\% of patients reported a history of alcohol-related ER visits. Most showed frequent excessive drinking, with an average of 21.3 days per month. In addition, 3 of 4 (75.0\%) participants had clinically significant psychiatric symptoms at baseline, meeting the DSM-IV criteria for clinical depression and anxiety disorders; although, it was difficult to distinguish whether these were pre-existing disorders or if they were caused by alcohol consumption or withdrawal. No psychotic symptoms were found at baseline. 
In the 6-month period following hospitalization, $26.1 \%$ of patients had had a medical follow-up for alcohol dependence. Alcohol consumption decreased in $36.5 \%$ of patients and remained unchanged in others compared with baseline values. Psychiatric symptoms were controlled in $18.2 \%$ of patients and emerged in $3.9 \%$. Changes in family life, both positive (26.2\%) and negative (16.7\%), were reported by $42.9 \%$ of the patients, while $21.2 \%$ reported changes in their social lives (positive, 12.9\%; negative, 8.2\%). Some participants (17.8\%) reported changed in their professional lives (positive, 10.7\%; negative, 7.1\%).

In univariate analysis (Table 2, model 1), the risk of alcohol-related ER visits over the 12- to 24-month period after hospitalization increased significantly in patients living with friends or parents $(\mathrm{p}<0.001)$, with a previous history of alcohol-related ER visits $(\mathrm{p}=0.037)$, who reported 6 to 7 DSM-IV criteria (out of 7) for alcohol dependence ( $p=0.019$ ), and who benefited from a medical follow-up in the 6 months after discharge $(\mathrm{p}=0.023)$. Some changes occurring within 6 months of discharge were also associated with increased risk, namely aggravated psychiatric morbidity $(\mathrm{p}<0.001)$; changes in family life, either positive $(\mathrm{p}=0.039)$ or negative ( $p=0.003)$; and negative changes in the participant's social life $(p=0.046)$. The risk of alcohol-related ER visits decreased significantly with age ( $\mathrm{p}=0.023)$, in patients living with children $(\mathrm{p}=0.036)$, and in those with improved psychiatric morbidity since hospitalization $(\mathrm{p}=0.029)$; while, the risk decreased marginally in those with decreased alcohol consumption $(\mathrm{p}=0.053)$. When variables predicting significantly ER visits in univariate analysis were entered into a multivariate model (Model 2), the risk of alcoholrelated ER visits was associated with the following: aggravated psychiatric conditions $(p=0.001)$, negative changes in family life $(p=0.004)$, a previous history of alcohol-related ER visits $(\mathrm{p}=0.006)$, medical follow-up in the 6 months following discharge $(\mathrm{p}=0.005)$, and living with friends/parents $(p=0.009)$. Living with children $(p=0.008)$ and improved psychiatric 
morbidity since hospitalization $(\mathrm{p}=0.042)$ remained significant protective factors in multivariate analysis. 


\section{Discussion}

The findings from this prospective study demonstrated that nearly half of patients hospitalized for detoxification had alcohol-related ER visits in the 12- to 24-month period following discharge; in addition, the living conditions and changes occurring within 6 months of discharge significantly influenced this outcome. The likelihood of ER visits was higher for patients living with friends/parents, with aggravated psychiatric symptoms, with negative changes in their family life, and who sought medical follow-up for alcohol dependence in the 6 months after discharge. In contrast, the likelihood of ER visits was lower for patients living with children and who had improved psychiatric morbidity since hospitalization. Alcohol consumption and psychiatric symptoms at baseline had no significant effect.

The high rate of alcohol-related ER visits recorded in our study sample in the 12- to 24-month period following discharge is concordant with long-term studies showing that detoxification benefits decrease significantly over time (Cutler and Fishbain, 2005, Dawson et al., 2007). The social characteristics of our participants, such as male gender, living alone, or psychiatric co-morbidities, were representative of patients hospitalized for alcohol issues in France, based on a 2010 investigation (OFDT, 2012). A history of ER visits for alcoholrelated issues was common (Whiteman et al., 2000) and significantly increased the risk of relapse in multivariate analysis, while disease severity did not. This could indicate that ER visits were not only related to medical conditions, but also to behavioral patterns that repeatedly put the patient at risk for injury or social issues (Zerhouni et al., 2013).

Living conditions and social networks might influence detoxification results differently. A cohort study found that living alone is associated with a substantially increased risk of alcohol-related mortality, irrespective of gender, socioeconomic status, or the specific cause of death (Herttua et al., 2011). Conversely, having close friends who are supportive of 
recovery and having no close friends who encourage the use of alcohol and other drugs is associated with remission (Satre et al., 2012). Living with parents or friends increased the likelihood of ER visits as compared with living alone or with a partner. In our adult patients, this could indicate the influence of housing difficulties and/or a unstable living environment. As living with children was a protective factor, our findings highlight the importance of the impact of living and family situations on treatment outcomes (Humphreys et al., 1996, Vanderplasschen et al., 2010). Conversely, alcohol consumption and psychiatric symptoms at baseline were not related to ER visits, confirming that the impact of early changes after participation in a detoxification program should be investigated.

Alcohol consumption decreased in more than 1 of 3 patients; while, psychiatric symptoms were controlled in nearly 1 of 5 patients in the 6 months after discharge. Nevertheless, alcohol and psychiatric patterns remained unchanged in most patients, confirming that moderation requires long-term efforts. An aggravated psychiatric condition in the 6 months after discharge was the most important predictor of ER visits in the following 18-month period; while, an improved psychiatric condition had a protective effect. Surprisingly, concomitant changes in alcohol consumption had no effect. It must be stressed that the causal relationship between psychiatric manifestations and alcohol-related issues is often unclear in patients with alcohol dependence/abuse (Hodgins et al., 1999). Alcohol might induce mental health issues or be used as self-medication for pre-existing or concomitant social and psychological issues (Brower et al., 2001, Swendsen et al., 2000, Strowig, 2000). Consequently, psychiatric symptoms could be due to alcohol misuse and may reflect an inability to cope with withdrawal, psychological distress, and/or life events; in addition, the symptoms could stem from a combination of these factors. However, as medical follow-up for alcohol dependence was associated with an increased risk of ER visits, our 
findings suggest that the treatment of detoxified patients after discharge should address both their alcohol dependence and related mental disorders to avoid further relapses and ER visits.

A significant proportion of patients experienced changes in family life after detoxification. Alcohol dependence/abuse can deeply affect diverse aspects of social functioning, especially family relationships (Moss, 2013). It is associated with intra-familial violence, divorce, and separation, and can have long-term consequences on children (Alonzo et al., 2014, Thompson et al., 2013). Given this background, it is not surprising that $16.7 \%$ of participants reported negative changes in family life after detoxification and these changes were a significant risk factor for ER visits in the following 18-month period. However, more than 1 in 4 patients (26.7\%) reported positive family changes, without any influence on ER visits. One possible explanation is that positive events, such as restoring or improving broken ties, can take place in families with ongoing conflicts. Improvements may occur sporadically within the context of upheaval and may fluctuate over time. The picture was quite different when it comes to participants' professional and social lives. They remained unchanged in most cases and did not influence subsequent ER visits. Taken together, our findings suggest that family trajectories and events could be investigated concomitantly with alcohol problems to establish adapted social support systems.

One limitation of this study was that social support and self-efficacy were not assessed; although, previous studies showed that these variables impact the relationship between life changes and health outcomes (Russell et al., 2001, Allsop et al., 2000). The relatively small size of the sample $(\mathrm{N}=88)$ may explain the lack of impact of some changes on ER visits, as in-depth determinant analyses may not be feasible on this sample size. Similarly, the influence of changes in psychiatric symptoms on treatment outcomes warrant further investigation given the small number of patients $(n=3)$ with aggravated psychiatric conditions in the present study. However, the prospective study design and the use of alcohol-related ER 
visits as repeated outcomes over an 18-month period may have limited this bias. Additional studies are needed to assess the impact of time-dependent covariates, such as life changes, social support, and psychiatric-co-morbidities, on alcohol-related issues in a larger cohort of patients following their participation in a detoxification program.

Finally, our findings suggest that changes in psychiatric symptoms and family life that occur soon after completing a detoxification program may be useful indicators of a patient's vulnerability to severe alcohol-related issues in the subsequent 18-month period. Systematic screening for such changes as early as possible, in combination with appropriate treatment and establishment of a social support system, could be fundamental to avoid further relapses and ER visits. 


\section{References}

Allsop S, Saunders B, Phillips M (2000) The process of relapse in severely dependent male problem drinkers. Addiction 95:95-106.

Alonzo D, Thompson RG, Stohl M, Hasin D (2014) The influence of parental divorce and alcohol abuse on adult offspring risk of lifetime suicide attempt in the united states. Am J Orthopsychiatry 84:316-320.

Brower KJ, Aldrich MS, Robinson EA, Zucker RA, Greden JF (2001) Insomnia, selfmedication, and relapse to alcoholism. Am J Psychiatry 158:399-404.

Cervantes EA, Miller WR, Tonigan JS (1994) Comparison of Timeline Follow-Back and Averaging Methods for Quantifying Alcohol Consumption in Treatment Research. Assessment 1:23-30.

Curran GM, Flynn HA, Kirchner J, Booth BM (2000) Depression after alcohol treatment as a risk factor for relapse among male veterans. J Subst Abuse Treat 19:259-265.

Cutler RB, Fishbain DA (2005) Are alcoholism treatments effective? The Project MATCH data. BMC Public Health 5:75.

Dawson DA, Goldstein RB, Grant BF (2007) Rates and correlates of relapse among individuals in remission from DSM-IV alcohol dependence: a 3-year follow-up. Alcohol Clin Exp Res 31:2036-2045.

Guerin S, Laplanche A, Dunant A, Hill C (2013) Alcohol-attributable mortality in France. Eur J Public Health 23:588-593.

Hasin D, Paykin A, Meydan J, Grant B (2000) Withdrawal and tolerance: prognostic significance in DSM-IV alcohol dependence. J Stud Alcohol 61:431-438.

Herttua K, Martikainen P, Vahtera J, Kivimaki M (2011) Living alone and alcohol-related mortality: a population-based cohort study from Finland. PLoS Med 8:e1001094.

Hodgins DC, el-Guebaly N, Armstrong S, Dufour M (1999) Implications of depression on outcome from alcohol dependence: a 3-year prospective follow-up. Alcohol Clin Exp Res 23:151-157.

Hoskins R, Benger J (2013) What is the burden of alcohol-related injuries in an inner city emergency department? Emerg Med J 30:e21.

Humphreys K, Moos RH, Finney JW (1996) Life domains, alcoholics anonymous, and role incumbency in the 3-year course of problem drinking. J Nerv Ment Dis 184:475-481.

King MP, Tucker JA (1998) Natural resolution of alcohol problems without treatment: environmental contexts surrounding the initiation and maintenance of stable abstinence or moderation drinking. Addict Behav 23:537-541.

Kline-Simon AH, Weisner CM, Parthasarathy S, Falk DE, Litten RZ, Mertens JR (2014) Five-year healthcare utilization and costs among lower-risk drinkers following alcohol treatment. Alcohol Clin Exp Res 38:579-586.

Korcha RA, Cherpitel CJ, Witbrodt J, Borges G, Hejazi-Bazargan S, Bond JC, Ye Y, Gmel G (2014) Violence-related injury and gender: the role of alcohol and alcohol combined with illicit drugs. Drug Alcohol Rev 33:43-50.

Lau-Barraco C, Collins RL (2011) Social networks and alcohol use among nonstudent emerging adults: a preliminary study. Addict Behav 36:47-54.

Lewis CE, Smith E, Kercher C, Spitznagel E (1995) Predictors of mortality in alcoholic men: a 20-year follow-up study. Alcohol Clin Exp Res 19:984-991.

Liskow BI, Powell BJ, Penick EC, Nickel EJ, Wallace D, Landon JF, Campbell J, Cantrell PJ (2000) Mortality in male alcoholics after ten to fourteen years. J Stud Alcohol 61:853861.

Mackenzie A, Funderburk FR, Allen RP, Stefan RL (1987) The characteristics of alcoholics frequently lost to follow-up. J Stud Alcohol 48:119-123. 
Minassian A, Vilke GM, Wilson MP (2013) Frequent emergency department visits are more prevalent in psychiatric, alcohol abuse, and dual diagnosis conditions than in chronic viral illnesses such as hepatitis and human immunodeficiency virus. J Emerg Med 45:520-525.

Moss HB (2013) The impact of alcohol on society: a brief overview. Soc Work Public Health 28:175-177.

OFDT (2012) Profil des patients en difficulté avec l'alcool accueillis à l'hopital [profile of hospitalized patients with alcohol disorders], in Series Profil des patients en difficulté avec l'alcool accueillis à l'hopital [profile of hospitalized patients with alcohol disorders], Vol. 82, Tendances, Observatoire Français des Drogues et Toxicomanie, Paris.

Pilowsky DJ, Keyes KM, Geier TJ, Grant BF, Hasin DS (2013) Stressful Life Events and Relapse Among Formerly Alcohol Dependent Adults. Soc Work Ment Health 11.

Russell M, Peirce RS, Chan AW, Wieczorek WF, Moscato BS, Nochajski TH (2001) Natural recovery in a community-based sample of alcoholics: study design and descriptive data. Subst Use Misuse 36:1417-1441.

Ruusa J, Bergman B, Sundell ML (2000) Alcohol Withdrawal, Psychological Symptoms, and Treatment Success. Subst Abus 21:129-135.

Satre DD, Chi FW, Mertens JR, Weisner CM (2012) Effects of age and life transitions on alcohol and drug treatment outcome over nine years. J Stud Alcohol Drugs 73:459468.

Sheehan DV, Lecrubier Y, Sheehan KH, Amorim P, Janavs J, Weiller E, Hergueta T, Baker R, Dunbar GC (1998) The Mini-International Neuropsychiatric Interview (M.I.N.I.): the development and validation of a structured diagnostic psychiatric interview for DSM-IV and ICD-10. J Clin Psychiatry 59 Suppl 20:22-33;quiz 34-57.

Snow D, Anderson C (2000) Exploring the factors influencing relapse and recovery among drug and alcohol addicted women. J Psychosoc Nurs Ment Health Serv 38:8-19.

Spinatsch M (1992) The prediction of long-term outcome of male alcoholics after inpatient treatment: the case of a clinical population in German-speaking Switzerland. Int J Addict 27:1087-1103.

Strowig AB (2000) Relapse determinants reported by men treated for alcohol addiction: the prominence of depressed mood. J Subst Abuse Treat 19:469-474.

Suter M, Strik W, Moggi F (2011) Depressive symptoms as a predictor of alcohol relapse after residential treatment programs for alcohol use disorder. J Subst Abuse Treat 41:225-232.

Swendsen JD, Tennen H, Carney MA, Affleck G, Willard A, Hromi A (2000) Mood and alcohol consumption: an experience sampling test of the self-medication hypothesis. $\mathrm{J}$ Abnorm Psychol 109:198-204.

Tamers SL, Okechukwu C, Bohl AA, Gueguen A, Goldberg M, Zins M (2014) The impact of stressful life events on excessive alcohol consumption in the French population: findings from the GAZEL cohort study. PLoS One 9:e87653.

Thompson RG, Alonzo D, Hasin DS (2013) Parental Divorce, Maternal-Paternal Alcohol Problems, and Adult Offspring Lifetime Alcohol Dependence. J Soc Work Pract Addict 13:295-308.

van Amsterdam J, van den Brink W (2013) Reduced-risk drinking as a viable treatment goal in problematic alcohol use and alcohol dependence. J Psychopharmacol 27:987-997.

Vanderplasschen WOI, Colpaert KAG, Broekaert EKM (2010) Determinants of relapse and re-admission among alcohol abusers after intensive residential treatment. Archives of Public Health 67:194-211. 
Walton MA, Ramanathan CS, Reischl TM (1998) Tracking substance abusers in longitudinal research: understanding follow-up contact difficulty. Am J Community Psychol 26:233-253.

White WL (2007) Addiction recovery: its definition and conceptual boundaries. J Subst Abuse Treat 33:229-241.

Whiteman PJ, Hoffman RS, Goldfrank LR (2000) Alcoholism in the emergency department: an epidemiologic study. Acad Emerg Med 7:14-20.

Witbrodt J, Kaskutas LA, Grella CE (2015) How do recovery definitions distinguish recovering individuals? Five typologies. Drug Alcohol Depend 148:109-117.

Wu LT, Swartz MS, Wu Z, Mannelli P, Yang C, Blazer DG (2012) Alcohol and drug use disorders among adults in emergency department settings in the United States. Ann Emerg Med 60:172-180 e175.

Yaogo A, Fombonne E, Kouanda S, Lert F, Melchior M (2014) Lifecourse Socioeconomic Position and Alcohol Use in Young Adulthood: Results from the French TEMPO Cohort Study. Alcohol Alcohol 49:109-116.

Young DJ, Stockwell T, Cherpitel CJ, Ye Y, Macdonald S, Borges G, Giesbrecht N (2004) Emergency room injury presentations as an indicator of alcohol-related problems in the community: a multilevel analysis of an international study. J Stud Alcohol 65:605612.

Zeger SL, Liang KY (1986) Longitudinal data analysis for discrete and continuous outcomes. Biometrics 42:121-130.

Zeger SL, Liang KY, Albert PS (1988) Models for longitudinal data: a generalized estimating equation approach. Biometrics 44:1049-1060.

Zerhouni O, Begue L, Brousse G, Carpentier F, Dematteis M, Pennel L, Swendsen J, Cherpitel C (2013) Alcohol and violence in the emergency room: a review and perspectives from psychological and social sciences. Int J Environ Res Public Health 10:4584-4606.

Zins M, Gueguen A, Leclerc A, Goldberg M (2003) Alcohol consumption and marital status of French women in the GAZEL cohort: a longitudinal analysis between 1992 and 1996. J Stud Alcohol 64:784-789.

Zureik M, Ducimetiere P (1996) High alcohol-related premature mortality in France: concordant estimates from a prospective cohort study and national mortality statistics. Alcohol Clin Exp Res 20:428-433. 
Table 1 (revised): Characteristics of the study participants and changes occurring in the 6 months after hospitalization

\begin{tabular}{|c|c|c|}
\hline \multicolumn{2}{|l|}{ Variables } & $\mathrm{N}(\%)$ \\
\hline \multicolumn{2}{|l|}{ Male Gender } & $73(83.0)$ \\
\hline \multicolumn{2}{|l|}{ Age, years } & $45.2(10.3)$ \\
\hline \multirow[t]{3}{*}{ Living status } & Alone & $50(56.8)$ \\
\hline & With a partner & $32(36.4)$ \\
\hline & With friends/Parents & $6(6.8)$ \\
\hline \multicolumn{2}{|l|}{ Living with children } & $23(26.1)$ \\
\hline \multicolumn{2}{|l|}{ High school graduate or more } & $32(36.4)$ \\
\hline \multirow[t]{2}{*}{ Professional life } & Currently employed & $62(70.5)$ \\
\hline & Unemployed/retired & $26(29.5)$ \\
\hline \multirow[t]{2}{*}{ Driving license status } & Active & $52(40.9)$ \\
\hline & Withdrawn/none & $36(59.1)$ \\
\hline \multicolumn{2}{|l|}{ Time since dependence onset (in years) } & $18.4(10.7)$ \\
\hline \multicolumn{2}{|c|}{ Number of excessive drinking days per month } & $21.3(9.0)$ \\
\hline \multirow[t]{3}{*}{ Number of DSMIV criteria for AD } & $6-7$ & $52(59.1)$ \\
\hline & $4-5$ & 19 (21.6) \\
\hline & 3 & $17(19.3)$ \\
\hline \multicolumn{2}{|l|}{ History of alcohol-related ER visits } & $55(62.5)$ \\
\hline \multicolumn{2}{|l|}{ Presence of Psychiatric morbidity } & $66(75.0)$ \\
\hline \multicolumn{2}{|c|}{ Follow-up treatment for $\mathrm{AD}$ in the 6 months after hospitalization } & $23(26.1)$ \\
\hline \multicolumn{3}{|c|}{ Changes in the following in the 6 months after hospitalization: } \\
\hline \multirow[t]{3}{*}{ Professional life } & Unchanged & $69(82.1)$ \\
\hline & Positive & $9(10.7)$ \\
\hline & & $0(1.1)$ \\
\hline \multirow[t]{3}{*}{ Social life } & Unchanged & $67(78.8)$ \\
\hline & Positive & 11 (12.9) \\
\hline & Negative & $7(8.2)$ \\
\hline \multirow[t]{3}{*}{ Family life } & Unchanged & $48(57.1)$ \\
\hline & Positive & $22(26.2)$ \\
\hline & Negative & $14(16.7)$ \\
\hline \multirow[t]{3}{*}{ Alcohol consumption } & Unchanged & $54(63.5)$ \\
\hline & Decreased & $31(36.5)$ \\
\hline & Increased & 0 \\
\hline \multirow[t]{3}{*}{ Psychiatric symptoms } & Unchanged & $60(77.9)$ \\
\hline & Controlled & $14(18.2)$ \\
\hline & Aggravated & 3 (3.9) \\
\hline
\end{tabular}


Table 2 (revised): Determinants of alcohol-related emergency room visits 12, 18, and 24 months after participation in a detoxification program. Rate ratios and 95\% confidence intervals (RR [95\% CI]) were estimated using Poisson regressions with autoregressive errors.

\begin{tabular}{|c|c|c|c|c|c|}
\hline \multirow{2}{*}{ Variable } & & \multicolumn{2}{|c|}{ Model 1} & \multicolumn{2}{|l|}{ Model 2} \\
\hline & & $\mathrm{RR}[95 \% \mathrm{CI}]$ & p-value & $\mathrm{RR}[95 \% \mathrm{CI}]$ & p-value \\
\hline Male Gender & & $0.63[0.27-1.44]$ & 0.273 & & \\
\hline Age (years) & & $0.97[0.94-0.99]$ & 0.023 & $0.98[0.95-1.01]$ & 0.193 \\
\hline Living status & $\begin{array}{c}\text { friends/Parents } \\
\text { With a partner } \\
\text { Alone }\end{array}$ & $\begin{array}{c}5.53[2.99-10.2] \\
0.63[0.21-1.84] \\
1\end{array}$ & $\begin{array}{c}<\mathbf{0 . 0 0 1} \\
0.397\end{array}$ & $\begin{array}{c}2.12[1.20-3.73] \\
2.38[0.89-6.42] \\
1\end{array}$ & $\begin{array}{l}\mathbf{0 . 0 0 9} \\
0.085\end{array}$ \\
\hline Living with children & & $0.49[0.25-0.95]$ & 0.036 & $0.35[0.16-0.76]$ & 0.008 \\
\hline High school level or more & & $0.92[0.46-1.87]$ & 0.829 & & \\
\hline Professional activity & $\begin{array}{l}\text { Currently active } \\
\text { Inactive/retired }\end{array}$ & $\begin{array}{c}0.69[0.29-1.63] \\
1\end{array}$ & 0.399 & & \\
\hline Driving license status & $\begin{array}{c}\text { Active } \\
\text { Withdrawn/none }\end{array}$ & $\begin{array}{c}0.69[0.32-1.48] \\
1\end{array}$ & 0.339 & & \\
\hline Time since dependence onset & & $0.98[0.95-1.02]$ & 0.446 & & \\
\hline Number of excessive drinking days $\mathrm{F}$ & r month $\dagger$ & $1.00[0.96-1.05]$ & 0.827 & & \\
\hline Number of DSMIV criteria for AD & $\begin{array}{c}6-7 \\
4-5 \\
3\end{array}$ & $\begin{array}{c}3.46[1.23-\mathbf{9 . 7 5}] \\
1.26[0.32-5.00] \\
1\end{array}$ & $\begin{array}{l}\mathbf{0 . 0 1 9} \\
0.744\end{array}$ & $\begin{array}{l}2.77[0.95-8.03] \\
1.30[0.35-4.77]\end{array}$ & $\begin{array}{l}0.061 \\
0.696\end{array}$ \\
\hline History of alcohol-related ER visits & & $2.51[1.06-5.94]$ & 0.037 & $2.92[1.35-6.31]$ & 0.006 \\
\hline Presence of Psychiatric morbidity & & $1.53[0.65-3.62]$ & 0.333 & & \\
\hline Follow-up treatment in the 6 month & after hospitalization & $2.42[1.13-5.19]$ & 0.023 & $1.97[1.23-3.15]$ & 0.005 \\
\hline \multicolumn{6}{|c|}{ Changes in the 6 months after a detoxification program } \\
\hline Professional life & $\begin{array}{c}\text { Negative } \\
\text { Positive } \\
\text { Unchanged }\end{array}$ & $\begin{array}{c}1.42[0.79-2.56] \\
1.01[0.49-2.10] \\
1\end{array}$ & $\begin{array}{l}0.239 \\
0.974\end{array}$ & & \\
\hline Social life & $\begin{array}{c}\text { Negative } \\
\text { Positive } \\
\text { Unchanged }\end{array}$ & $\begin{array}{c}\mathbf{1 . 7 9}[\mathbf{1 . 0 1}-\mathbf{3 . 1 7}] \\
1.40[0.55-3.55] \\
1\end{array}$ & $\begin{array}{l}\mathbf{0 . 0 4 6} \\
0.974\end{array}$ & $\begin{array}{c}2.29[0.89-5.90] \\
1.16[0.43-3.19] \\
1\end{array}$ & $\begin{array}{l}0.087 \\
0.764\end{array}$ \\
\hline Family life & $\begin{array}{c}\text { Negative } \\
\text { Positive } \\
\text { Unchanged }\end{array}$ & $\begin{array}{c}2.67[1.39-5.20] \\
2.75[1.05-7.19] \\
1\end{array}$ & $\begin{array}{l}0.003 \\
0.039\end{array}$ & $\begin{array}{c}\mathbf{2 . 6 9}[\mathbf{1 . 3 6}-\mathbf{5 . 3 0}] \\
2.05[0.84-5.02] \\
1\end{array}$ & $\begin{array}{l}\mathbf{0 . 0 0 4} \\
0.114\end{array}$ \\
\hline Alcohol consumption $\ddagger$ & $\begin{array}{l}\text { Decreased } \\
\text { Unchanged }\end{array}$ & $\begin{array}{c}0.46[0.21-1.01] \\
1\end{array}$ & 0.053 & $\begin{array}{c}1.01[0.52-1.95] \\
1\end{array}$ & 0.973 \\
\hline Psychiatric symptoms $† \dagger$ & $\begin{array}{l}\text { Aggravated } \\
\text { Improved } \\
\text { Unchanged }\end{array}$ & $\begin{array}{c}9.68[3.18-29.4] \\
0.16[0.03-0.82] \\
1\end{array}$ & $\begin{array}{c}<0.001 \\
0.029\end{array}$ & $\begin{array}{c}7.32[2.21-24.2] \\
0.22[0.05-0.94] \\
1\end{array}$ & $\begin{array}{l}0.001 \\
0.042\end{array}$ \\
\hline
\end{tabular}

Significant results $(\mathrm{p}<0.05)$ are marked in bold; $\uparrow$ : Assessed with the Alcohol TimeLine Follow back method; $\ddagger$ : Adjusted for the number of excessive drinking days per month at baseline; $\dagger$ : Adjusted for psychiatric symptoms at baseline; $\mathrm{AD}=\mathrm{Alcohol}$ Dependence 


\section{Table Legends:}

Table 1: Characteristics of the study participants and changes occurring in the 6 months after hospitalization

Table 2: Determinants of alcohol-related emergency room visits 12, 18, and 24 months after participation in a detoxification program. Rate ratios and 95\% confidence intervals (RR [95\% $\mathrm{CI}]$ ) were estimated using Poisson regressions with autoregressive errors. 